\title{
Significant Climate Warming (1950-2013) in the Spanish Mediterranean: Natural Trend or Urban Heat Island (UHI)
}

\author{
J. Quereda ${ }^{1}$, E. Montón ${ }^{1}$, V. Quereda ${ }^{1}$ and B. Mollá ${ }^{1}$ \\ ${ }^{1}$ Climate Laboratory, Universitat Jaume I
}

Received: 28-IV-2016 - Accepted: 7-X-2016 - Original version

Correspondence to: quereda@uji.es

\begin{abstract}
This investigation completes the line of work on the thermal evolution of the Mediterranean region (Murcia and Valencia regions) in the National Plan on Climate Change. The study was undertaken to analyse the active regional thermal series over the 1950-1999 period, rigorously treated by the SNHT (Standard Normal Homogeneity Test) method. In this context, fifteen years later, it was considered judicious to verify the validity of the trends and conclusions that the regional climate offered at the end of the 20th century. The objectives of this study are twofold: the verification of the Significant Climate Warming in the Spanish Mediterranean concluded in the National Plan on Climate Change (1950-1999) and the evaluation of the importance that the Urban Heat Island (UHI) has on the warming process. Within the context of the thermal evolution of the region over the 1950-2013 period, this verification has been supported by an experimental research plan aimed at analysing the thermal processes inherent to the urbanisation effect. Although the effect is undeniable, its importance is a matter of controversy. The results obtained have shown both the nature of the phenomenon and its significant magnitude. This magnitude could account for between 70 and $80 \%$ of the recorded warming trend in Western Mediterranean cities. Therefore, failure to take this process into account might seriously bias any analysis of regional thermal evolution, the main aim of this study and an aim that equally affects the hypothesis of global climate change.
\end{abstract}

Key words: Temperatures, urban effect, heat island, homogeneity, climate change

\section{Introduction}

Significant systematic research work has been carried out on climate variations and human influence on the climate in the last two decades. The starting point may be deemed the Earth Summit in Rio (1992). The intense study activity is justified by the current hypotheses on our climate future. However, despite the formidable efforts made to control data quality, numerous uncertainties persist in this domain in full effervescence, in which swings of half a degree, or perhaps more, must be carefully examined as they could stem from a simple change of shelter or relocation of the observatories.

This entire series of non-climatic processes makes any analysis of regional or global temperature evolution bristle with difficulties and uncertainties. Such uncertainties are posed, in particular, by the historical series of the main world observatories. This analysis cannot be readily carried out, as certain non-climatic processes must be taken into account, the subtlest and most important of these undoubtedly being the urban heat effect. Cities have become cells or bubbles of very different climate conditions from those of the atmospheric or rural surroundings in which they are located. This process, known as the urban heat island (UHI), may have been underestimated, as it could otherwise constitute a real Achilles heel in temperature evolution analyses (IPCC 2001, 2007).

The answers put forward by the scientific community show that, though the UHI effect seems undeniable, its importance is highly controverted. The IPCC scientific protocols themselves, while recognising the microclimate 
effect of cities, indicate that this effect is only local and practically negligible in the regional or global trend. Thus, according to these IPCC scientific bases, the magnitude of the UHI would not have exceeded $0.002^{\circ} \mathrm{C}$ per decade since 1900 and, under the influence of the ocean, the global UHI of the trend would tend to zero (IPCC 2007). In short, while it may be accepted that urban heating is of local importance, there is no evidence that it alters the global temperature trend (IPCC 2001).

However, the IPCC Fifth Assessment Report (2013) has begun to profoundly review those scientific considerations and bases regarding the UHI. Analyses of the process in China and in other industrialised areas have drawn further attention to these issues. Thus, on comparing the temperature of urban areas and rural areas, various researchers have concluded that the urban effect could account for between $40 \%$ and $80 \%$ of the observed thermal trend in the last few decades (Ren et al. 2007; Yan et al. 2010). At the same time, in the USA, McKitrick and Michaels (2007) concluded that half the warming trend observed between 1980 and 2002 could stem from changes in the land uses. It has been attempted to weight or reduce these magnitudes by satellite radiation and reanalysis measurements (Parker 2011; Jones et al. 2012; Vose et al. 2012). However, these reductions have not precluded a profound revision of the statements of the IPCC's fourth report (2007). Thus, Efthymiadis and Jones (2010) concluded that the urban influence would currently be $0.02^{\circ} \mathrm{C}$ per decade and up to $15 \%$ of the global warming trend recorded between 1951 and 2009.

In short, the IPCC itself today already unquestionably recognises that the UHI has a real influence on the temperature series. This effect moreover, which is assigned a limit magnitude of $15 \%$, could be much greater in certain industrialised regions of the planet.

Consequently, the effect has led to a reduction in global warming forecasts for the horizon of the year 2100 , with a probable global value ranging from $1.5^{\circ} \mathrm{C}$ to up to $2^{\circ} \mathrm{C}$ (IPCC 2013).

\section{Thermal evolution in the Western Mediterranean}

\subsection{Observatories and Data}

As we have said, the basic scientific objective in this study has been to establish, with the greater possible rigor, the trends displayed by regional climatology between 1950 and 2013. This verification required taking into account the thermal series recorded at the regional observatories. The AEMET (Spanish Meteorology Agency) regional network, after the quality control processes, consists of 22 observatories (Fig. 1) that, with series of over sixty years cover the 1950-2013 period. The base data (AEMET) have been the monthly temperature measurements.

\subsection{Data Quality}

Given that the validity of any conclusions on the evolution of the climate depends on the quality of the data, all the series used in this paper have undergone a certain number of quality control operations. The first of these consisted in testing the continuity and spatial coherence of the measurements. The values skewed from statistical significance as well as the gaps (due to a lack thereof or those generated in the quality control) have been indicated and reconstructed with the help of a simple interpolation using the averages from the nearest weather stations and those with the best correlation coefficient, $r>0.7$.

\subsection{Homogeneity of the temperature time series}

All this demands awareness of the enormous difficulties inherent to the verification of the true causes of the climate warming, owing to the great heterogeneity in the temporal thermal series. Indeed, despite rigorous use of the most sophisticated statistical techniques in the analysis, the insecurity in the detection of heterogeneities, and consequently of significant trends, continues to persist throughout the conclusions reached on the magnitude of the observed warming. These difficulties justify the ongoing quest for comparative techniques of homogenisation algorithms. A large number of homogenization methods have been developed in recent decades (Mitchell et al. 1966; Sneyers 1975; Easterling and Peterson 1992; Lamarque and Jourdain 1994; Easterling et al 1997; Moberg and Alexandersson 1997, Peterson et al. 1998; Quereda et al. 2000; Ducre-Robitaille et al. 2003; Beaulieu et al. 2008; Venema et al. 2012, Mestre et al. 2013).

The techniques used in this study are based on the Standard Normal Homogeneity Test (SNHT), a methodology set by Alexandersson (1986), with the revisions by Easterling and Peterson (1992), and Möberg and Alexandersson (1997). This methodology provides one of the greatest approaches to the problem of how to treat homogeneity in the temporary climatic series today and it also fully responds to our proposed scientific objective: to verify the warming trend showing the series of regional temperatures in the National Climate Plan (1950-1999).

In this test, a series is defined as homogenous when it is compared with a synchronous reference series and the differences in temperature and relative humidity between the simultaneous weather stations constitute a series of random numbers. In order to do this, a reference series must be defined. This series must imperatively show characteristics of homogeneity and good correlation with the series studied. However, even if it is easy to find a nearby weather station in good correlation with the studied series for each weather station to be tested, it still proves to be complicated to characterize the internal homogeneity of each series. This makes it necessary to calculate an average reference series 


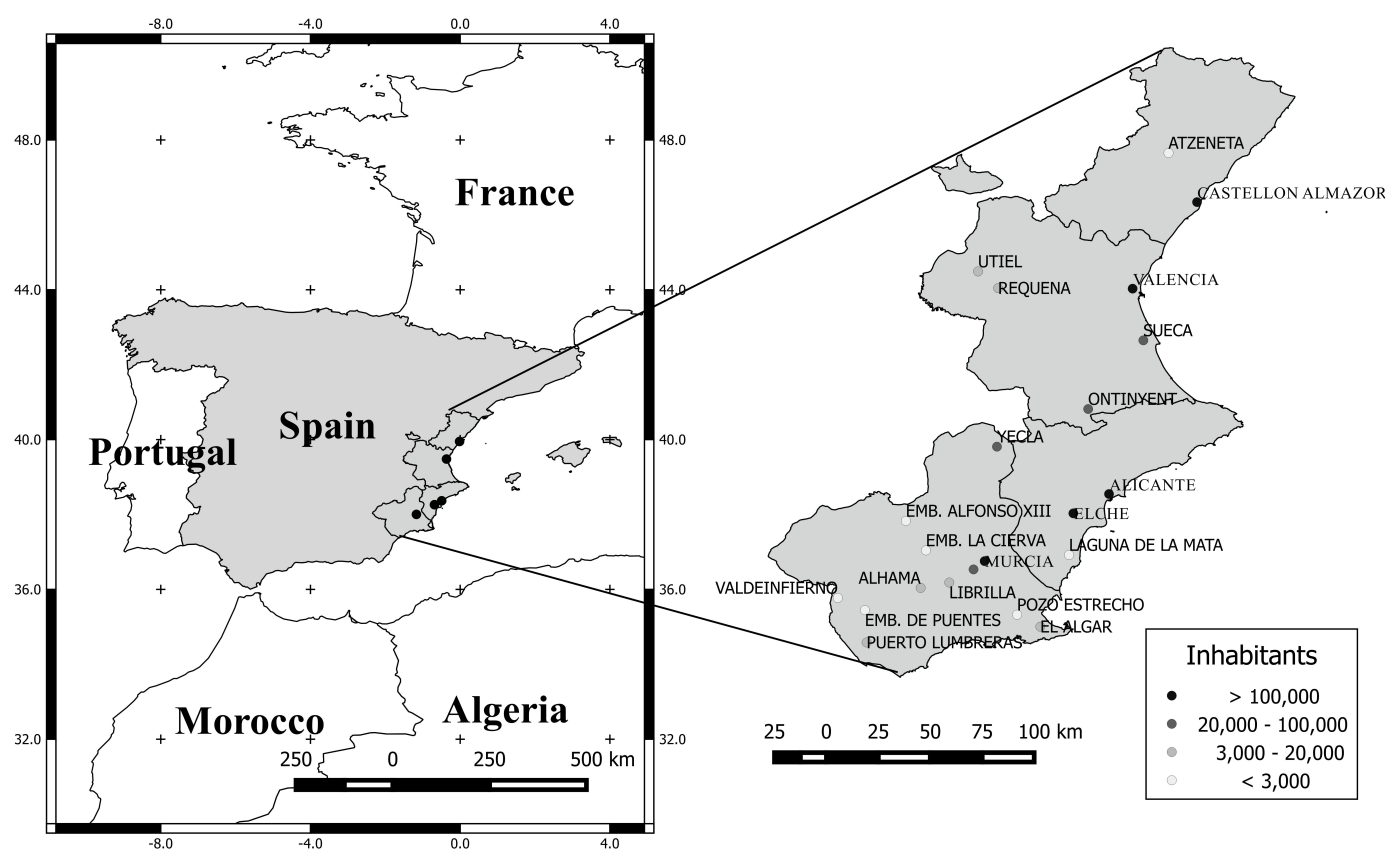

Figure 1. Map of the regional network of observatories with complete temperature series over the 1950-2013 period. Source: AEMET and our own graph.

with the different series and one in which the heterogeneities are blurred.

Certainly, herein lies one of the few weaknesses of the method. The method consists of averaging homogenous series, or at least attempting to lessen the effect of the ruptures in the inhomogeneous series, which, unfortunately, seem to be most of them. If this makes it possible for the majority of homogeneity ruptures in the tested series to be detected, then it is crucial to bear in mind that the corrective coefficients deduced from the series of differences or ratios might be skewed. To correct a series by using a reference series generally implies equalizing the trends of the corrected series and the reference series. In addition, if the quality of the reference series is not reliable, which is the case a priori, the results might be distorted. It is for this reason that in our previous work (Quereda et al. 2000), we adopted a precaution, which was to eliminate the clearly non-homogenous series with a correlation coefficient of less than 0.7 from the reference calculation.

A reference specific to each weather station is calculated in this way. The calculation consists of a weighted average using the squares of the correlation coefficients so that each series has the specific weight that corresponds to it in the configuration of the reference series. This way, a series is formed with the differences in the various tested values.

In this normalized series, the test tries to discover a change with respect to the mean. For each passage of time, month or year, the test value is calculated and compared to the critical value for a determined threshold. Should the critical value be exceeded, then heterogeneity is considered to exist. The most probable date for a rupture in homogeneity corresponds to the maximum value of the test.

With all these processes, the SNHT test makes it possible for us to consider whether a series is random or not, in addition to the possible heterogeneities. Should they arise, the different heterogeneities must be corrected.

\subsection{Correction of the heterogeneities}

In this, the third and most laborious phase, all these ruptures in homogeneity were corrected using the date shown by the SNHT test. However, it is necessary to point out that we have endeavoured to verify and confirm such ruptures by means of the historical records of each of the weather stations, without being detrimental to the present unknowns, and specifically for those ruptures for which the test is conceived. Indeed, the causes of the rupture can be diverse and not necessarily explained in these historical records. The period considered to be homogenous is the one situated before the date of the rupture. The method used for the correction of the heterogeneities consists of establishing the difference between the mean of the period in the series to be corrected and the average of the period in the homogenous series, and then to add this difference to 

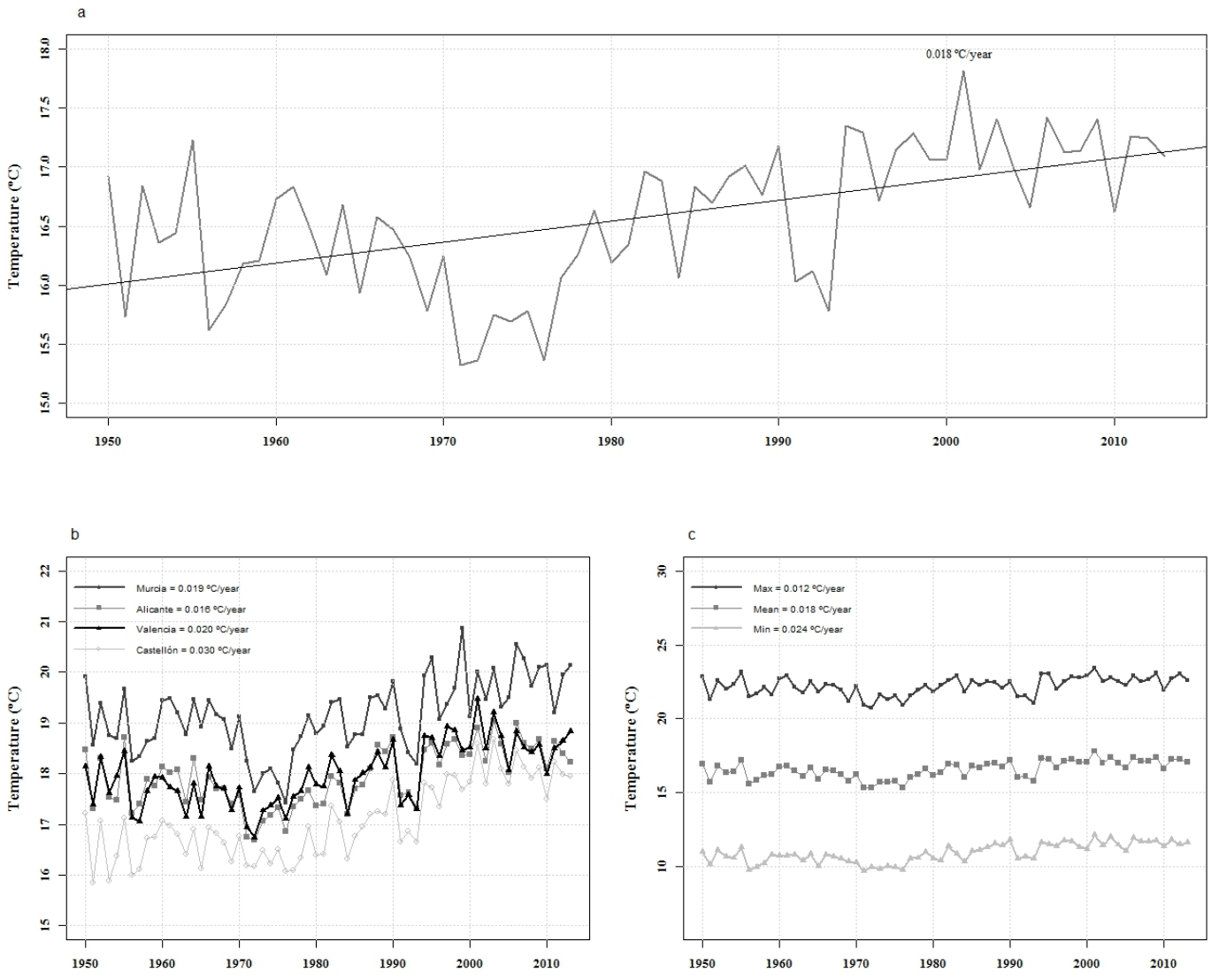

Figure 2. Evolution and trend (1950-2013) (a) of mean annual temperatures in the Murcia and Valencia regions on averaging all the observatories of the regional network and (b) of mean annual temperatures of four urban observatories: Murcia, Alicante, Valencia, and Castellón and (c) of mean annual maximum and minimum temperatures in the regional network of observatories with their trends. All the trends are significant at 0.05 level. Source: AEMET and our own graph.

the values of the series to be corrected. In order to calculate the average, a formula proposed by Alexandersson (1986) has been used. All the same, more than one rupture might arise. In this case, the method proposed by Easterling and Peterson (1992) was employed. This method consists of detecting a first rupture, splitting the series in two, and then continuing the application of the detection process for each of the sub-series. The correlation coefficients between the treated series should show a good correlation.

\subsection{Results of the regional temperature evolution}

The analysis results evidenced a climate warming trend in the temperature evolution of the Spanish Mediterranean region. The annual value of this trend was notable: $0.018^{\circ} \mathrm{C} /$ year, equivalent to $1.12^{\circ} \mathrm{C}$ for the $1950-2013$ period. This value even acquired "dramatic" warming magnitudes, as it only began to be detected from 1980 on, after a relatively cool preceding decade (Fig. 2a).

However, both the "abrupt" rise from 1980 on and the different warming magnitudes recorded between very close-lying observatories: $+0.030^{\circ} \mathrm{C} /$ year in Castellón, $+0.020^{\circ} \mathrm{C} /$ year in Valencia, $+0.019^{\circ} \mathrm{C} /$ year in Murcia, and only $+0.016^{\circ} \mathrm{C} /$ year in Alicante, as well as the different behaviour of the maximum and minimum temperatures, raised doubts with regard to the nature and magnitude of the (anthropogenic or natural) change and its very existence (Quereda et al. 2000) (Fig. 2b).

Consequently, the arising doubts regarding the true warming trends urge trend analysis, in particular, because part of the temperature rise could stem from the urbanisation effect. As noted above, this effect has been evidenced progressively and cumulatively, as the observatories have been gradually enveloped by the cities in their expansion. The result of this process may be reflected in the fact that most of the regional thermal rise occurred in the minimum temperatures, with a value of $1.5^{\circ} \mathrm{C}$ over the $1950-2013$ period (Fig. 2c), while the maximum temperatures marked a value of $0.78^{\circ} \mathrm{C}$.

Certainly, our results are opposite to those obtained by Brunet et al. (2007). However, that upward trend in the minimum temperature caused by urbanization, in the 
centres.

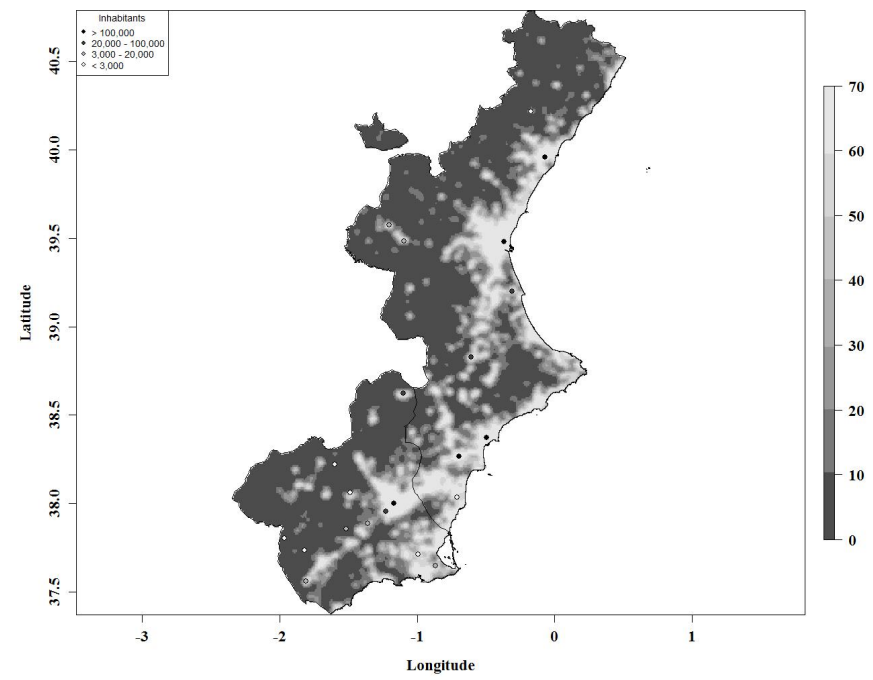

Figure 3. Map of nighttime lights (2013) from the Operational Linescan System (OLS) instrument in Defense Meteorological Satellite Program (DMSP) satellites. The units are Digital Number Values from 0 - 63 for visible band data. It includes the location of the network of observatories, classified by its population. Source: Image and data processing by NOAA's National Geophysical Data Center (NOAA's National Geophysical Data Center, Version 4 DMSP-OLS Nighttime Light Series); DMSP data collected by US Air Force Weather Agency. US Air Force Weather Agency; our own graph.

Mediterranean coastal areas, is corroborated by Horcas et al. (2001), Miró et al. (2006) and recently by Gonzalez Hidalgo et al. (2015). A controversial regional trend that reinforces the scientific uncertainty about the behaviour of DTR (diurnal temperature range), according to Easterling et al. (1997) and Folland et al. (2001).

Consequently, the urban heat generation process persists as one of the main uncertainties in identifying the nature and magnitude of the regional climate warming trend. This is not surprising, as the trend has been evidenced in the records of historical observatories. In the case at issue, the Mediterranean observatories were established at the end of the 19th century on city outskirts, becoming progressively enveloped by the growth of the cities (Fig. 3), with effects that need to be identified as they might be disguising the true climate trends. Failure to take the Trojan effect, such as the malicious noise of a computer program, into account could entail introducing great bias and error into the verification of the magnitude of climate warming. This is evinced by the great difference in the trend between observatories located in big cities and in smaller centres (Fig. 4).

The verified behaviours of the maximum and minimum temperatures thus led to a reduction of the mean daily thermal amplitude (Fig. 5). The reduction was notable in the urban centres as a result of the effect on the minimum temperatures, whereas it was hardly noticeable in the rural

\section{An "experimental" analysis of the urban thermal effect}

In view of the above, the urban thermal effect could be a true Trojan in the analysis of thermal evolution. This means that the true "natural rise" of the temperature, corrected for the urbanisation effect, might be much smaller than that suggested by current studies and models, or even nonsignificant. Moreover, it justifies rigorous investigation of a process that could be seriously biasing the study of thermal evolution, the veritable axis of the climate change hypothesis (Lee 1992, Quereda et al. 2000). The recent PNACC (National Plan on Climate Change in Spain, MIMAM 2007), in its introduction, notes: "to plan an adaptation for a warming horizon of $2^{\circ} \mathrm{C}$ is not the same as to plan one for a warming horizon of $4^{\circ} \mathrm{C}$ ".

\subsection{The observation arrangement}

The above issues led us to undertake a specific analysis of the urban thermal effect, through the temperature evolution at the dawn of the 21st century (2001-2014) and using AVHRR infrared imagery. The evolution corresponds to the records of five observation stations located in the Castellón city area, a city that has witnessed a notable demographic increase in recent years: in 1970 the city had 93,000 inhabitants, whereas in 2010 it had close to 200,000 inhabitants. The urban and industrial area in the municipalities of Castellón and Almazora has increased from $3.20 \mathrm{~km}^{2}$ in 1945 to $25.36 \mathrm{~km}^{2}$ in 2014 (Figs. 6a and $6 b)$.

Of those five observation stations, four observatories (Casino Antiguo, UJI, Port and Islet) belong to the Universitat Jaume I network of automatic meteorological stations, while the fifth belongs to the first-order Castellón-Almazora observatory (AEMET, Spanish Meteorological Agency). The observatories, shown in Fig. 6b, were selected to record the temperature in the urban centre of Castellón de la Plana (Casino Antiguo) and, at the same time, on the city outskirts (AEMET, UJI, Port, and Islet observatories). All these stations were each rigorously calibrated with two instruments (CASELLA-DAVIS). With a view to having the freest aerological conditions, in the Casino Antiguo central observatory, the station located $5 \mathrm{~m}$ above the terrace was used; at the UJI, the outside on-campus station was used, while the data of the port station and of the marine station on the BP Oil Platform, the station farthest removed from urban influence, were averaged. 


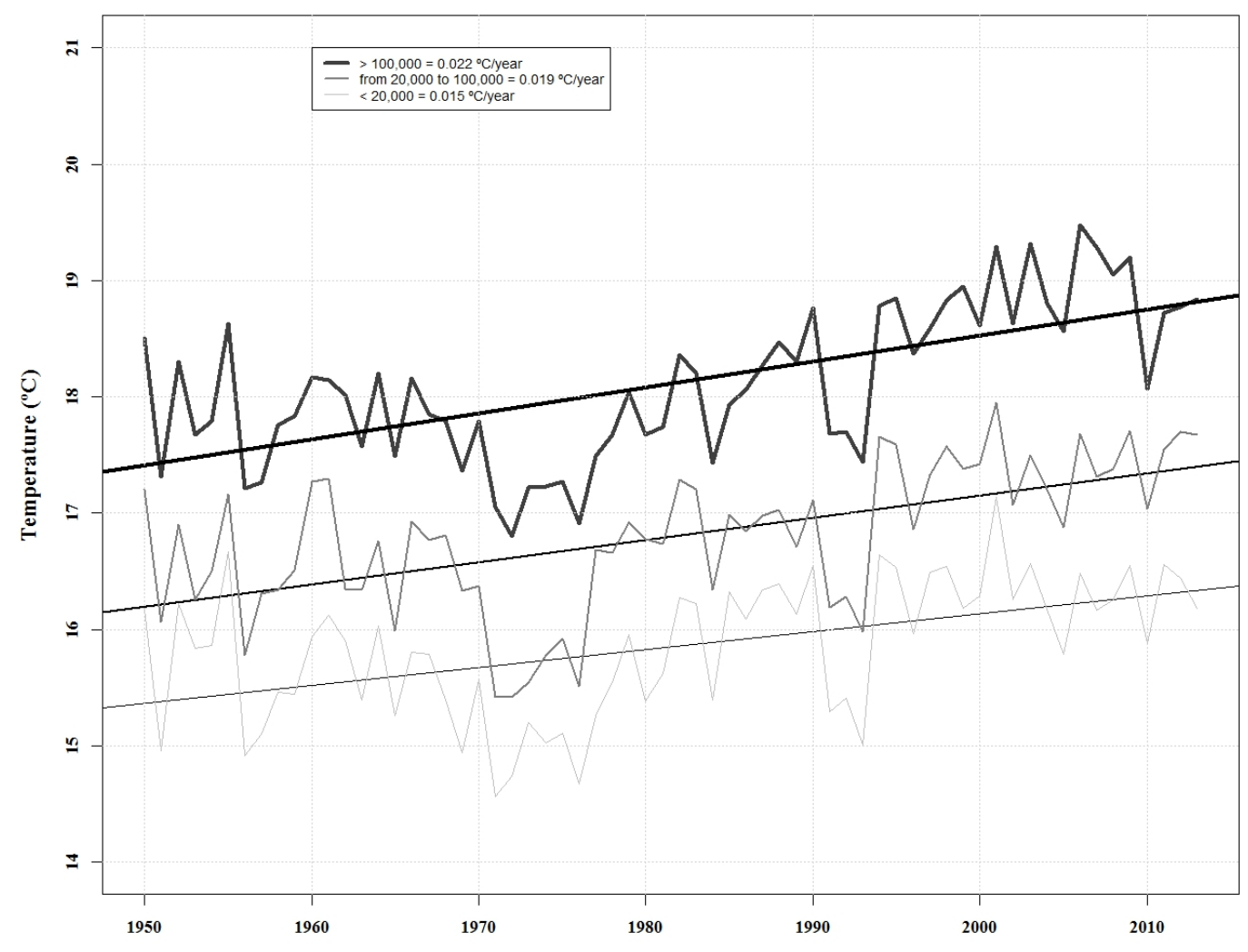

Figure 4. Evolution and trend of mean annual temperatures in the urban observatories of Murcia, Elche, Alicante, Valencia, Castellón (> 100,000 inhabitants), as well as in the other "more rural" observatories in the Valencia and Murcia regions (1950-2013). All the trends are significant at 0.05 level. Source: AEMET and our own graph.

\subsection{Results of the experimental analysis}

The meteorological records analysed here cover the first thirteen years of the 21st century, the 2001-2013 period. In this period, together with the operation of the AEMET (Spanish Meteorological Agency) observatory, the four automatic meteorological stations of the university network were constantly controlled and calibrated. The resulting analysis, in a period of acceptable length, was thus extremely rigorous in all records and the experiment may be deemed of high value with regard to the UHI (Urban Heat Island) effect.

A great difference can be observed between the mean annual temperature (Fig. 7) of the Casino Antiguo station in the city centre, $18.8^{\circ} \mathrm{C}$, and that of the other three meteorological stations located on the urban outskirts (AEMET, UJI, and Port), with mean records of $17.4^{\circ} \mathrm{C}$ (UJI), $18.1^{\circ} \mathrm{C}$ (AEMET), and $17.8^{\circ} \mathrm{C}$ (Port). The mean value of the Port station was almost identical to that recorded at the BP Oil Islet station $\left(17.9^{\circ} \mathrm{C}\right)$, at $14 \mathrm{~m}$ above sea level and in the air-sea interface with a SST (Sea Surface Temperature) of $19.0^{\circ} \mathrm{C}$.
These results allowed the great magnitude that the UHI may be acquiring at observatories currently recording their data within urban areas to be evaluated. Thus, assuming that the observatories on the Castellón city outskirts were unaffected by the influence of urban heat, the value of the UHI with respect to the urban centre (Casino) would swing between $0.7^{\circ} \mathrm{C}$ with respect to the AEMET observatory and $1.4^{\circ} \mathrm{C}$ and $1^{\circ} \mathrm{C}$ with respect to the UJI and Port stations, respectively. This magnitude would be even greater, because the same observatories located on the urban outskirts can also be affected by the urban influence.

This urban influence constituted the true nature of the process, evidenced by the differentiated thermal gradient found between the mean maximum temperatures and the mean minimum temperatures (Fig. 7) of the urban centre and the outskirts. Indeed, the mean minimum temperatures exhibited a difference of $2^{\circ} \mathrm{C}$ between the university station (UJI) and the Casino, and a difference of $1.7^{\circ} \mathrm{C}$ between the Casino and AEMET observatories. However, in this order of mean minimum temperatures, there appears to be an anomaly in the same temperature recorded at the Casino and the Port stations $\left(15.2^{\circ} \mathrm{C}\right)$. This further highlights the great influence 


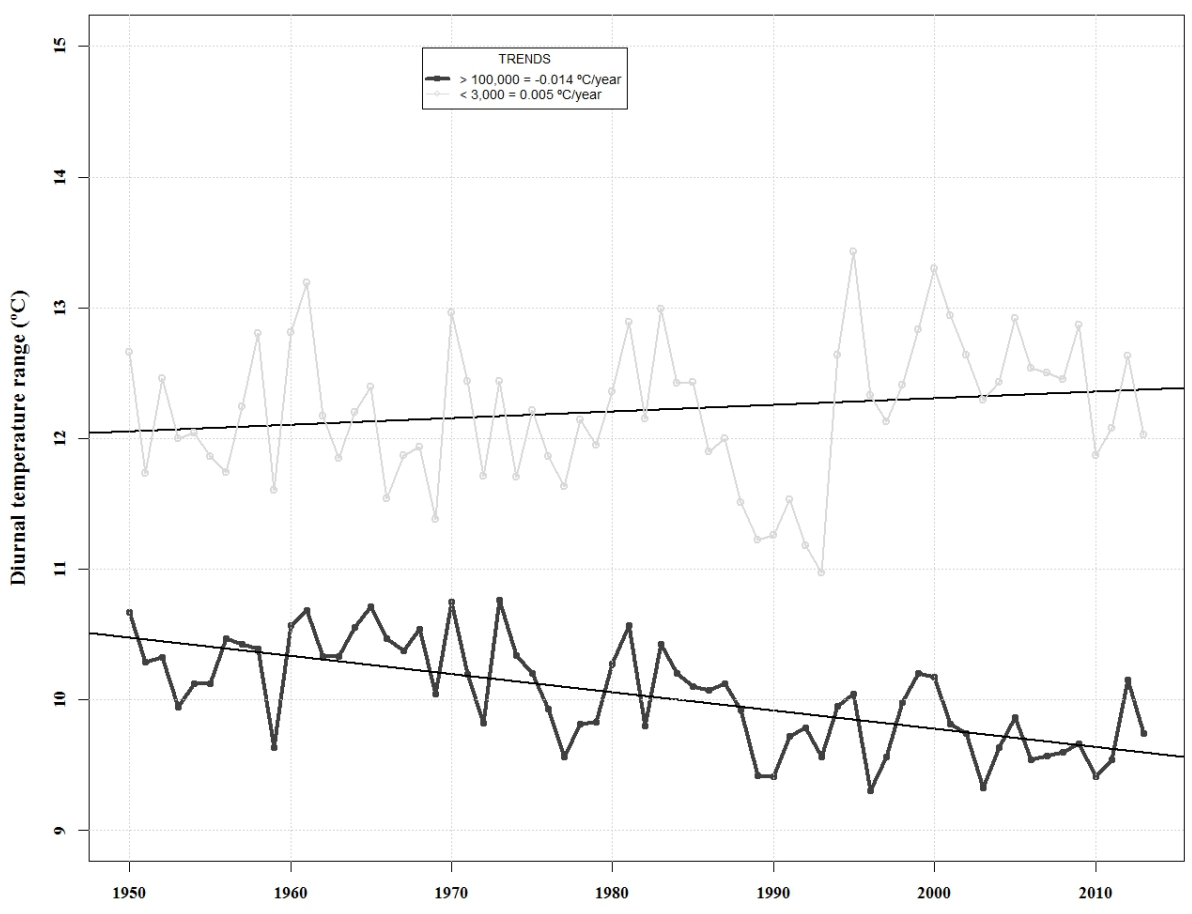

Figure 5. Evolution of the DTR (diurnal temperature range) of the urban observatories $(>100,000$ inhabitants) and rural observatories $(<$ 3,000 inhabitants). The trend for rural observatories is not significant at 0.05 level. Source: AEMET and our own graph.

that variations in the surroundings have on thermal records. Thus, the Port station, located at the end of the harbour dyke of the lighthouse, acted as an annual atmosphere-sea interface governed by a mean annual SST of $19.9^{\circ} \mathrm{C}$ and $14.9^{\circ} \mathrm{C}$ in the mean minimum temperatures. The thermostatic role of the sea was shown to be determinant.

\section{Detection of the UHI thermal effect through NOAA-AVHRR imagery}

The imagery used in this piece of work comes from the NOAA-KLM series, AVHRR $/ 3^{1}$ remote sensor. The methodology combined information in the visible and near infrared (VIS/NIR) bands in terms of NDVI, and also in the thermal infrared (TIR) bands to extract Land Surface

\footnotetext{
${ }^{1}$ AVHRR: Advanced Very High Resolution Radiometer, this sensor provides multispectral information in the range from visible to thermal infrared through six channels: Channels 1 ( 0.58 to 0.68 $\mu \mathrm{m})$, and $2(0.725$ to $1.10 \mu \mathrm{m})$ take albedo data from 0 to $25 \%$. Channel $3(1.6 \mu \mathrm{m})$ uses the first part of its dynamic range $(3 \mathrm{~A})$ to detect albedo from 0 to $12.5 \%$. The second part of channel 3 (3B) is shared with a channel in the near infrared $(3.7 \mu \mathrm{m})$. Finally, channels 4 and 5 filter out the thermal infrared (from 10.8 to 11.5 $\mu \mathrm{m}$ respectively) and they are used to extract information about temperatures.
}

Temperatures (LST). LST determinations from satellite data are influenced by the atmosphere and surface emissivity. In order to obtain accurate estimations of this parameter, we applied a split-window algorithm. First of all, pixels contaminated by clouds had to be eliminated. Thus, we used several cloudiness tests to detect cloud free pixels. The next step was to estimate the effective surface emissivity by applying the procedure developed by Sobrino and Raissouni (2000). Their technique is known as the Normalized Difference Vegetation Index (NDVI) thresholds. They also use the atmospheric water vapour estimations from only satellite data. And finally, they apply a split-window algorithm that uses the brightness temperature of the channels 4 and 5 of the AVHRR to implement the atmospheric correction.

$T_{4}+1.4\left(T_{4}-T_{5}\right)+0.32\left(T_{4}-T_{5}\right)^{2}+$

$+0.83+(57-5 W)(1-\epsilon)-(161-30 W) \Delta \epsilon$

where $T_{4}$ and $T_{5}$ are the brightness temperatures measured in AVHRR channels 4 and 5 respectively, $\epsilon=\left(\epsilon_{4}+\epsilon_{5}\right) / 2$ and $\Delta \epsilon=\left(\epsilon_{4}-\epsilon_{5}\right)$ and $W$ is the water vapour parameter; $\epsilon$ is the emissivity from thermal infrared radiance data (Planck function, Channel Emissivity).

The surface temperatures have been analysed at critical moments in the process of the UHI generation. The imagery shows the existence of the heat focus produced by urban 


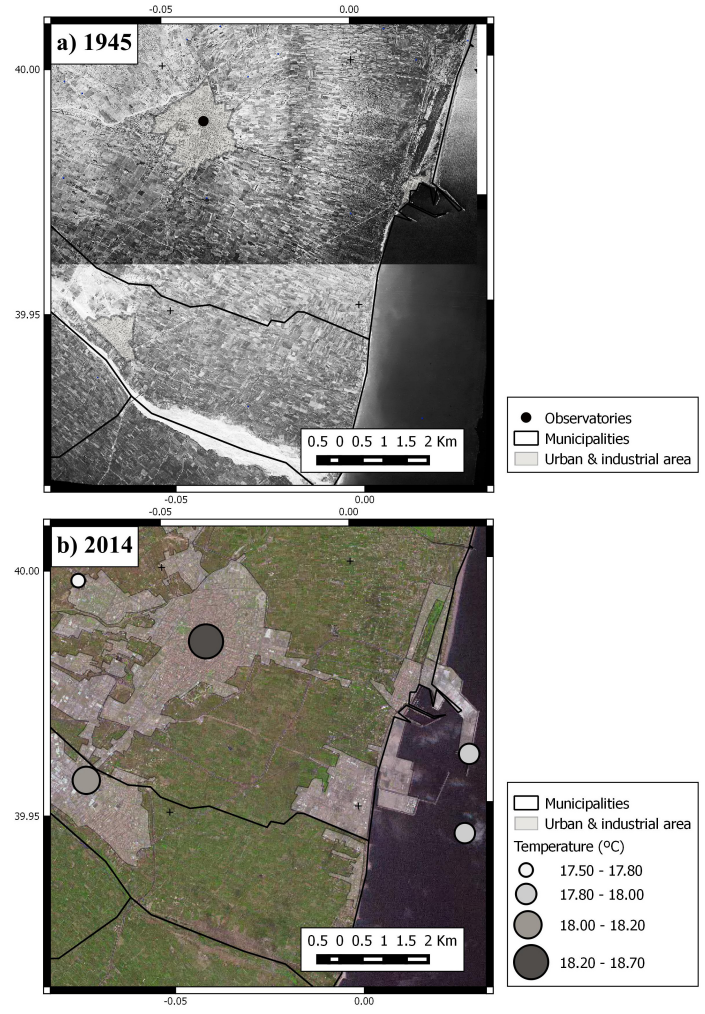

Figure 6. Network of stations used in this study showing the increasing urbanization in the Castellon metropolitan area. The Ribalta High School, where the AEMET observatory was located until 1975, is shown in 1945 picture. Source: IGN (Instituto Geográfico Nacional. Digital Photographic Library, http://fototeca.cnig.es/ Accessed: 2015, May 6th) and our own graph.

areas and human activities. This is especially clear in the nocturnal imagery and early in the mornings, when the UHI is seen in its sharpest and most contrasted view. Nevertheless, the diurnal imagery and hours of maximum sunshine are less clear and show poor contrast between urban and rural areas. This is due to the low soil conductivity and the high thermal elevation that it can experience during the hours of direct solar incidence. Therefore, the thermal effects of dry soils and scarce vegetation can be of the same or even greater magnitude than those produced by the air cells that constitute the urban places.

Fig. 8 shows two nocturnal images of the Eastern Spanish coast. The first one is from the 5th of August, 2003, where the perfect delimitation of the urban areas is clearly seen because they have the warmest tones. The littoral urbanization and the concentration of human activities register readings of more than $30^{\circ} \mathrm{C}$. Those high temperatures contrast with the low values in the rural areas, showing big thermal gradients. In big cities like Barcelona and Valencia, the heat cells spread out further, though that effect can be also observed over the Palma de Mallorca bay.

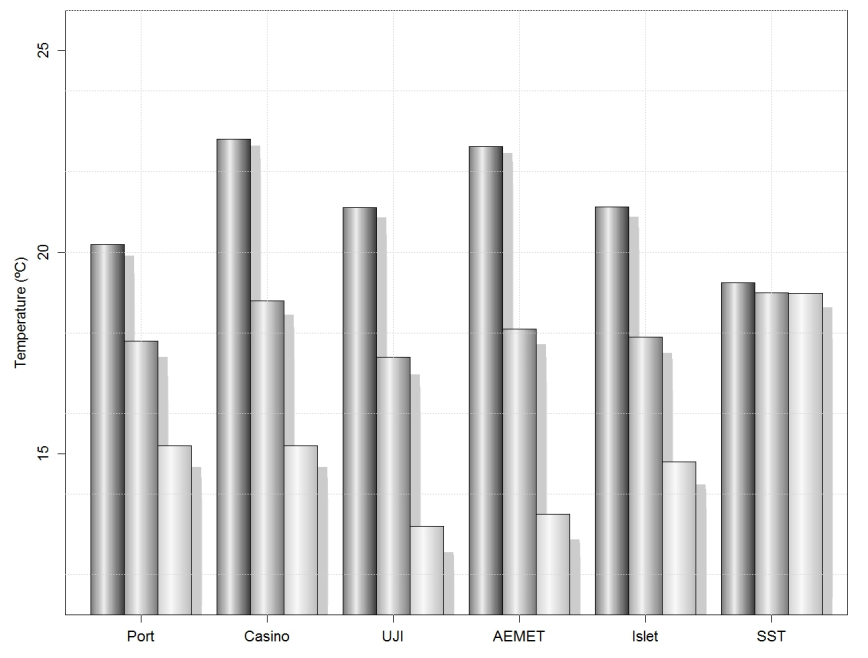

Figure 7. Mean maximum, mean annual and mean minimum temperatures at the different observatories (2001-2013). Source: AEMET and Climate Laboratory, Universitat Jaume I.

The map on the right part of Fig. 8 is an image of the same coast line, at a similar time of night, about 22 UTC, but during the winter season, the 12th of February of 2004. As can be seen, the UHI is also visible; though less intense. Barcelona and Valencia are easily distinguishable but on the southern coast (Alicante and Murcia) the urban contrast is weaker.

\section{Conclusions}

Are urban areas contributing to the observed warming trend on which climate change is based?

This study completes the line of work on thermal evolution in the Mediterranean region (Murcia and Valencia regions) in the National Plan on Climate Change. In this context, fifteen years later, this investigation has verified, at the 2013 level, the validity of the thermal trends that the regional climate displayed at the end of the 20th century. The investigation has also allowed confirmation, in particular, of the true nature of those climate warming trends owing to their link to the urban effect. Although this UHI (Urban Heat Island) effect is undeniable, its importance is a matter of controversy. The results obtained in the university network of automatic stations and at the AEMET observatory allow the UHI (Urban Heat Island) to be deemed a true Trojan in the analysis of regional and global temperature evolution. In these Western Mediterranean cities, the UHI could account for up to $80 \%$ of the recorded warming.

This raises a vital question in the regional and global rising-temperature process. Are urban areas contributing to the observed warming trend on which climate change 


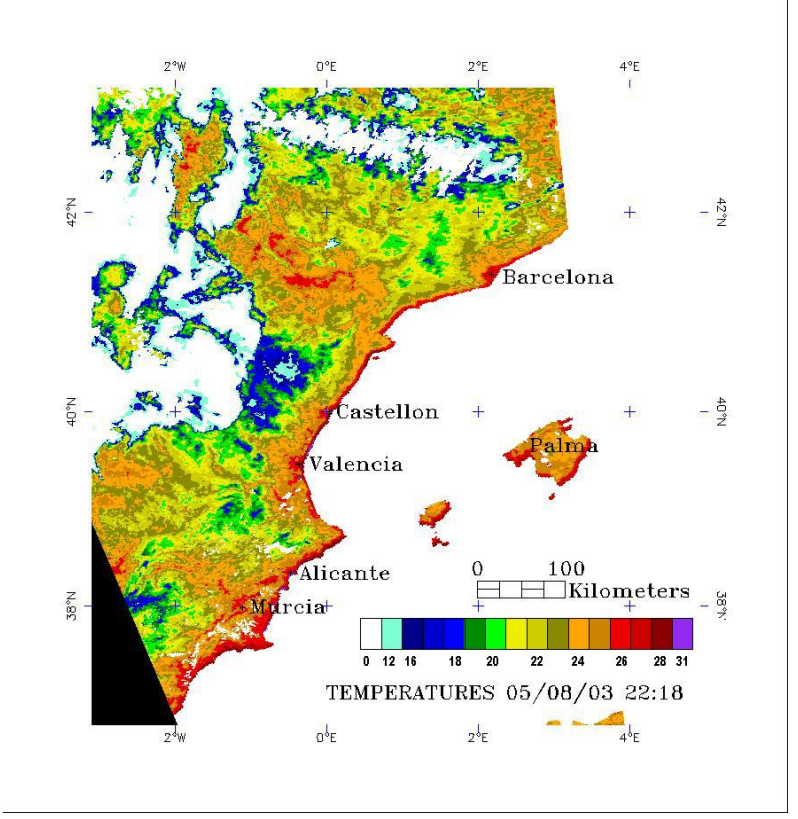

(a)

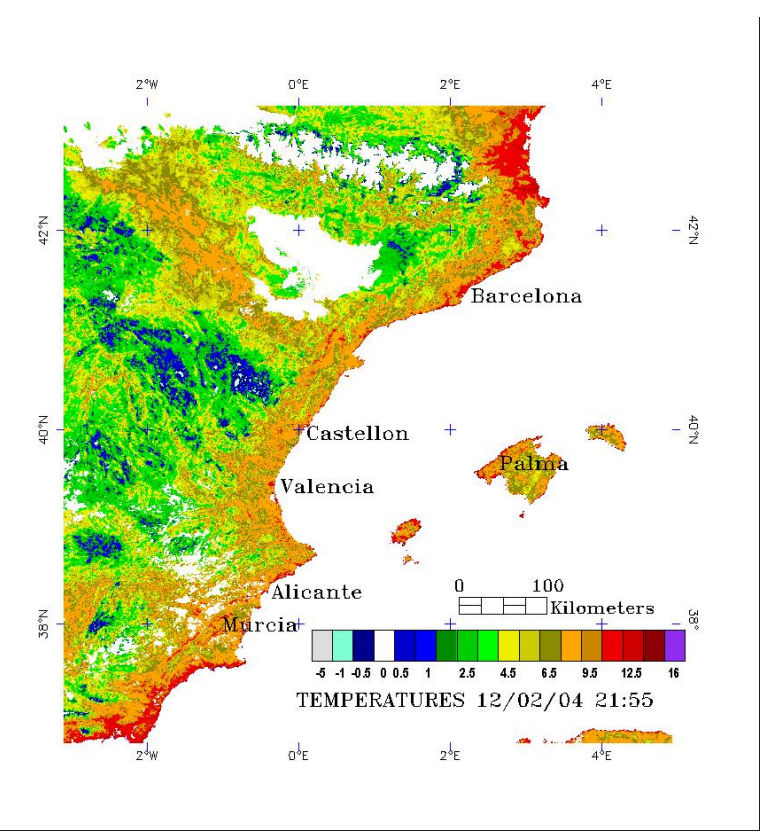

(b)

Figure 8. Temperature maps of the Eastern Spanish coast. Left: 5th August 2003; right: 12th February 2004.

is based? The answer to be drawn from our analysis is fully affirmative. This answer, at least in the Mediterranean region, then leads to the question: What temperature would currently be obtained in the historical series of the Mediterranean region if the urban effect were removed? This question might be answered, without extrapolation to other contexts, through the thermal evolution recorded in the two historical observatories closest to the area investigated.

\section{References}

Alexandersson, H., 1986: A homogeneity test applied to precipitation data, Int. J. Climatol., 6, 661-675.

Alexandersson, H. and Moberg, A., 1997: Homogenization of Swedish temperature data. Part I: Homogeneity test for linear trends, Int. J. Climatol., 17, 25-34, doi: 10.1002/(SICI)10970088(199701)17:1<25:AID-JOC103>3.0.CO;2-J.

Beaulieu, C., Seidou, O., Ouarda, T., Zhang, X., Boulet, G., and Yagouti, A., 2008: Intercomparison of homogenization techniques for precipitation data, Water Resour. Res., 44, w02425, doi:10.1029/2006WR005615.

Brunet, M., Jones, P., Sigro, J., Saladie, O., Aguilar, E., Moberg, A., Della-Marta, P. M., Lister, D., Walther, A., and Lopez, D., 2007: Temporal and spatial temperature variability and change over Spain during 1850-2005, J. Geophys. Res., 112:D12117.

Ducré-Robitaille, J-F., V. L. and Boulet, G., 2003: Comparison of techniques for detection of discontinuities in temperature series, Int. J. Climatol., 23.

Easterling, D. R. and Peterson, T. C., 1992: Techniques for detecting and adjusting for artificial discontinuities in climatological time series: a review, 5th International Meeting on Stat. Climatology.
Easterling, D. R., Horton, B., Jones, P. D., Peterson, T. C., Karl, T. R., De Parker, D. E., Salinger, M. J., Razuvayev, V., Plummer, N., Jamason, P., and Folland, C. K., 1997: Maximum and minimum temperature trends for the globe, Science, 277, 364-367.

Folland, C. K., Karl, T. R., Christy, J. R., Clarke, R. A., Gruza, G. V., Jouzel, J., Mann, M. E., Oerlemans, J., Salinger, M. J., and Wang, S. W., 2001: Observed climate variability and change, in Climate Change 2001: The scientific basis. Contribution of Working Group I to the Third Assessment Report of Intergovernmental Panel on Climate Change, edited by Houghton, J. T., Ding, Y., Griggs, D. J., Noguer, M., van der Linden, P. J., Dai, X., Maskell, K., and Johnson, C. A., Cambridge Univ. Press, New York., p. 99-182.

Folland, C. K., Karl, T. R., Christy, J. R., Clarke, R. A., Gruza, G. V., Jouzel, J., Mann, M. E., Oerlemans, J., Salinger, M., Efthymiadis, D. A., and Jones, P. D., 2010: Assessment of Maximum Possible Urbanization Influences on Land Temperature Data by Comparison of Land and Marine Data around Coasts, Atmosphere, 1, 51-61.

Gonzalez-Hidalgo, J. C., Peña-Angulo, D., Brunetti, M., and Cortesi, N., 2015: MOTEDAS: a new monthly temperature database for mainland Spain and the trend in temperature (1951-2010), Int. J. Climatol., p. 4444-4463.

Horcas, R., Rasilla, D., and Fernandez Garcia, F., 2001: Temperature variations and trends in the Segura River Basin. An exploratory analysis. In Detecting and Modelling Regional Climate Change, Brunet M, Lopez D. (eds)., Springer-Verlag: Heidelberg, Germany, p. 133-142.

Houghton, J. T., Ding, Y., Griggs, D. J., Noguer, M., van der Linden, P. J., Dai, X., Maskell, K., and Johnson, C. A.: IPCC., 2001: Climate Change., 2001: The Scientific Basis. Contribution of Working Group I to the Third Assessment Report of the Intergovernmental Panel on Climate Change, cambridge 
University Press, Cambridge, United Kingdom and New York, NY, USA, $881 \mathrm{pp}$.

Jones, P. D., Lister, D. H., Osborn, T. J., Harpham, C., Salmon, M., and Morice, C. P., 2012: Hemispheric and large-scale landsurface air temperature variations: An extensive revision and an update to 2010, J. Geophys. Res.:Atmospheres, 117 D51027, doi: 10.1029/2011JD017139.

Lamarque, P. and Jourdain, S., 1994: Élaboration de longues séries climatologiques homogènes pour l'étude de l'évolution climatique, La Météorologie, 8e série, 7, 61-69.

Lee, D. O., 1992: Urban warming? An analysis of recent trends in London's heat island, Weather, 47, 50-56.

Mckitrick, R. R. and Michaels, P. J., 2007: Quantifying the influence of anthropogenic surface processes and inhomogeneities on gridded global climate data, J. Geophys. Res.:Atmospheres, 112.

Mestre, O., Domonkos, P., Picard, F., Auer, I., Robin, S., Lebarbier, E., Böhm, R., Aguilar, E., Guijarro, J., Vertacnik, G., Klancar, M., Dubuisson, B., and Stepanek, P., 2013: HOMER: HOMogenisation softwarE in $R$ - methods and applications, Idöjárás, 117, 47-67.

MIMAM, 2007: Plan Nacional de Adaptación al Cambio Climático, Oficina Española de Cambio Climático.

Miro, J. J., Estrela, M. J., and Millan, M., 2006: Summer temperature trends in a Mediterranean area (Valencia, Spain), Int. J. Climatol., 26, 1051-1073.

Mitchell, J. R., Dzerdzeevskii, J. M., Flohn, H., Hoymeyr, W. L., Lamb, H. H., Rao, K. N., and Wallen, C. C., 1966: Climatic Change, T. Note No.79 WMO.

Moberg, A. and Alexandersson, H., 1997: Homogenization of Swedish temperature data, Part II: Homogenized gridded air temperature compared with a subset of global gridded air temperature since 1861, Int. J. Climatol., 17, 35-54.

Parker, D. E., 2011: Recent land surface air temperature trends assessed using the 20th century Reanalysis, J. Geophys. Res.: Atmospheres, 116.

Peterson, T., Easterling, D., Karl, T., Groisman, P., Nicholls, N., Plummer, N., Torok, S., Auer, I., Böhm, R., Gullett, D., Vincent, L., Heino, R., Tuomenvirta, H., Mestre, O., Szentimrey, T., Salinger, J., Førland, E. J., Hanssen-Bauer, I., Alexandersson, H., Jones, P., and Parker, D., 1998: Homogeneity adjustments of in situ atmospheric climate data: a review, Int. J. Climatol., 18, 1493-1517.

Quereda Sala, J., Gil Olcina, A., Olcina Cantos, J., Rico Amorós, A., Montón Chiva, E., and Escrig Barberá, J., 2000: Climatic warming in the Spanish Mediterranean. Natural Trend or Urban effect, Climatic Change, 4, 473-483.

Ren, G. Y., Chu, Z. Y., Chen, Z. H., and Ren, Y. Y., 2007: Implications of temporal change in urban heat island intensity observed at Beijing and Wuhan stations, Geophysical Research Letters.

Sneyers, R., 1975: Sur l'analyse statistique des séries d'observations. Note technique $n^{o}$ 143, Organisation Météorologique Mondiale, Geneva.

Sobrino, J. A. and Raissouni, N., 2000: Toward remote sensing methods for land cover dynamic monitoring. Application to Morocco, International Journal of Remote Sensing, 2, 353-366.

Solomon, S., Qin, D., Manning, M., Chen, Z., Marquis, M., Averyt, K. B., Tignor, M., and Miller, H. L.: IPCC., 2007: Climate Change 2007: The Physical Science Basis. Contribution of Working Group I to the Fourth Assessment Report of the Intergovernmental Panel on Climate Change, cambridge
University Press, Cambridge, United Kingdom and New York, NY, USA, 996 pp.

Stocker, T. F., Qin, D., Plattner, G. . K., Tignor, M., Allen, S. K., Boschung, J., Nauels, A., Xia, Y., Bex, V., and Midgley, P. M.: IPCC., 2013: Climate Change 2013: The Physical Science Basis. Contribution of Working Group I to the Fifth Assessment Report of the Intergovernmental Panel on Climate Change, cambridge University Press, Cambridge, United Kingdom and New York, NY, USA, 1535 pp.

Venema, V. K. C., Mestre, O., Aguilar, E., Auer, I., Guijarro, J. A., Domonkos, P., Vertacnik, G., Szentimrey, T., Stepanek, P., Zahradnicek, P., Viarre, J., Müller-Westermeier, G., Lakatos, M., Williams, C. N., Menne, M. J., Lindau, R., Rasol, D., Rustemeier, E., Kolokythas, K., Marinova, T., Andresen, L., Acquaotta, F., Fratianni, S., Cheval, S., Klancar, M., Brunetti, M., Gruber, C., Prohom Duran, M., Likso, T., Esteban, P., and Brandsma, T., 2012: Benchmarking Homogeneization Algorithms for Monthly Data, Clim. Past, 8, 89-115.

Vose, R. S., Applequist, S., Menne, M. J., Williams Jr., C. N., and P., T., 2012: An intercomparison of temperature trends in the US Historical Climatology Network and recent atmospheric reanalyses, Geophysical Research Letters, 39.

Yan, Z. W., Li, Z., Li, Q. X., and Jones, P., 2010: Effects of site change and urbanisation in the Beijing temperature series, 19772006, Int. J. Climatol., 30, 1226-1234. 